\title{
Contribution of Solar Energy for Sustainable Urban Development in Rwanda
}

\author{
Hirwa Gloria ${ }^{1, *}$, Hakizabera Olivier ${ }^{2,3}$, Ishimwe Marie Angella ${ }^{4}$ \\ ${ }^{1}$ School of Architecture and Design, Beijing Jiaotong University, China \\ ${ }^{2}$ China Western Research Center of Energy \& Environment, Lanzhou University of Technology, China \\ ${ }^{3}$ Gansu Key Laboratory of Complementary Energy System of Biomass and Solar energy, China \\ ${ }^{4}$ School of Chemistry and Bioengineering, Lanzhou Jiaotong University, China
}

Received September 19, 2019; Revised September 26, 2019; Accepted October 5, 2019

Copyright@2019 by authors, all rights reserved. Authors agree that this article remains permanently open access under the terms of the Creative Commons Attribution License 4.0 International License

\begin{abstract}
In this century development, some African countries are now still facing a challenge of lack of electricity, because hydropower and thermal fuel are still on a small scale. This problem results in less economic productivity decline of some countries like Rwanda which is among African countries that are at a very high speed in development, and the grid lines are few compared to the need for electricity, especially in rural areas whereby each household needs power usage instead of using local and traditional means of ironing and lighting at home. This issue can be solved using Renewable Energy for rural electrification such as Photovoltaic systems. Therefore, this paper reviews Solar Energy for Sustainable Urban Development in Rural Area (Rwanda). Under this work, case study result will focus on one village in Rwanda named as" Agahozo- Shalom Youth Village (ASYV) located in Rwamagana district in Eastern Rwanda. The project is the first utility-scale, grid-connected, commercial solar field in East Africa. The field is $8.5 \mathrm{MW}$ of grid-connected power to 15,000 homes and it increased Rwanda's generation capacity by $6 \%$. Solar urban design is a phase of sustainable urban planning that will facilitate development and could provide new solutions to the world's energy problem by reducing its consumption and improving the performance of future buildings. The main mission of this article is to care for Rwanda's most vulnerable children, is leasing land to house the solar facility, and the fees from which will help pay for a portion of the Village's charitable.
\end{abstract}

Keywords Rural Electrification, Renewable Energy, Off-Grid PV Systems, Grid Lines, Sustainable Urban Development

\section{Introduction}

The application of renewable energies contributes to global warming prevention and as a matter of fact, photovoltaic systems have been increasingly developed in recent years due to the global benefit of natural resources conservation. It is also evident that fossil fuel-based energy sources will be depleted over time since they are finite and consequently, they have been proven to contribute to global climate change[1].To protect our environment and increase electricity access in remote areas, green and clean energy alternatives like solar energy, absorbed by photovoltaic systems can be of great importance. In Rwanda, there is a serious problem of electricity access especially in rural areas, which is very crucial in affecting the sustainable development of the country. The current situation shows that the grid connection is estimated to be around $23 \%$, whereby rural villages that are connected to the national grid account for only $5 \%$ and in addition, statistics show that $85 \%$ of Rwandan population live in rural areas while only $15 \%$ accounts for urban citizens [2]. The most common activity observed in these areas is farming for food provision and other life basic needs security. For the case of Rwanda with many populations in rural areas, there is a challenge of energy extension and development in other economic sectors. The topology of the electric grid in Rwanda is another important aspect. There is presently insufficient electrical power to compensate for electricity demand in Rwanda, most of which produced from different power plants are distributed to urban areas and business centers [3, 4]. The power supply is done using single lines because the transmission network is very radial in nature. Grid extension is affected by economic constraints such as high cost of electricity that is not affordable for rural consumers as well as geographical conditions, and therefore, it's hard for poor people living in far distances from grid lines to get power. 
In fact, there is a lack of alternate paths for electricity in transmission network and notably, the power service related to rural areas and this has a negative impact on pushing village residents to move in cities. In this paper vulnerability of rural areas for providing the more reliable and typical solution for rural electrification in Rwanda will be presented and discussed.

\section{Materials and Methods}

\subsection{Basic Operation Mechanism of the Photovoltaic Cell}

A complete electricity-management system using PV as its source for power will contain, in addition to the photovoltaic array, one or more of the following:

- $\quad$ Storage device

- $\quad$ Power-conditioning equipment, including devices to limit current and voltage in order to maximize power output.

- $\quad$ Converting direct current to alternating current

- Matching the converted DC electricity to the utility's AC electrical network

- $\quad$ Safeguarding the utility network and its personnel from possible damage caused by the PV system.

There are two basic forms of electricity: alternating current (AC) and direct current (DC). The difference between them is that the alternating current (AC) is made up of electrons alternately flowing in one direction and then in the opposite direction under the influence of a cycling force (voltage) that acts a part of a time in one and then the opposite direction, while for DC electricity, the electrons flow in a single direction and it is generated by devices such as batteries and photovoltaic systems as shown in Fig 1. In a battery, electrons gather at an electrode as the result of a chemical reaction within the battery. In the PV cell, the electrons are generated by light and the ability of the PV cell to move charge carriers to opposite sides of the cell. The electrons move because there is a driving force, a voltage which is characteristic of the electric source, for example, an electrochemical cell (battery) or a PV cell. Direct current is a perfectly useful form of electricity for many applications. At an isolated location, there is no need to do anything more than use PV-generated electricity and perhaps store it for times when there is no daylight to activate the cells. This is possible so long as the devices being powered can use direct current. But some of motors and applications can't be designed for direct current. PV arrays are useful energy producers only when the sun is shining on them and thus are unproductive in a good deal of the time. This extends the availability of electricity through periods when there is no illumination. If a utility grid is convenient to the PV system, then it can be used as a low-cost way to store electricity. Excess electricity from the PV system can be suitably made compatible with grid electricity. When more PV electricity is being generated than is being used, the excess can be metered and fed to the grid. When the PV system is not providing enough power, the extra amount needed can be purchased from the utility grid.

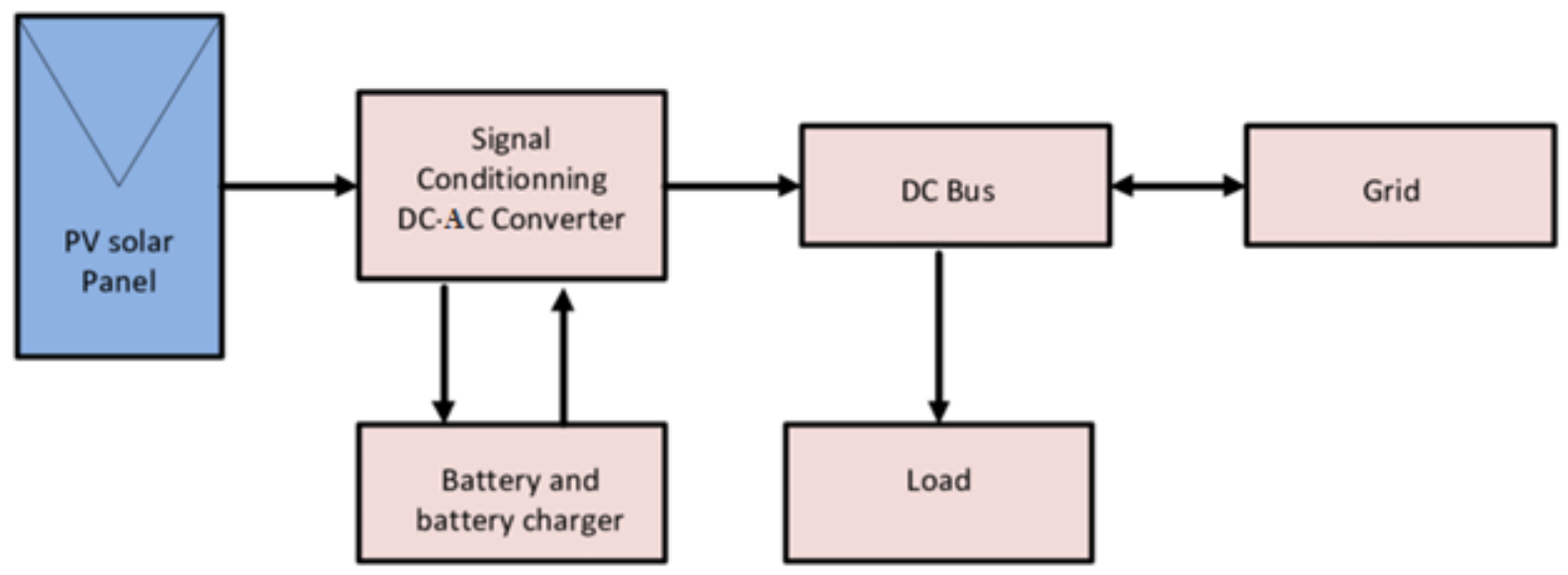

Figure 1. General diagram of the PV system showing the main components 


\subsection{Methodology}

The methodology for Sustainable Solar Urban Planning is based on comparing the existing urban area with the possible gains if the Rural Area is changed in development using the process in sustainable urban planning. The new developments' results will focus on social, economic and governance factors with solar energy use.

This method will guarantee the effectiveness and prosecution of the sustainability principles and accurately predict solar energy production in urban areas subjected to renewal or regeneration processes.

\section{Project Description}

Rwanda's solar radiation and solar resources were assessed by the U.S. National Air and Space Agency (NASA) as well as the University of Rwanda. Rwanda's Eastern Province has the greatest potential for generating energy from solar resources. Another academic assessment, undertaken in partnership with the MININFRA Department of Meteorology in 2007, used a meteorological data set to estimate monthly averaged global solar radiation. Rwanda's daily solar irradiation ranges from $4 \mathrm{kWh} / \mathrm{m}^{2}$ to $5.4 \mathrm{kWh} / \mathrm{m}^{2}$. Season to season conditions vary with average daily irradiation in the cloudy reaching about 4.5 $\mathrm{kWh} / \mathrm{m}^{2}$ and the total annual potential is estimated to be around 66.8 TWh [5].

Rwanda solar energy is very high even during the rainy seasons and there is daily and sufficient sunshine especially in the Eastern province which is known for high irradiance values as it is indicated on the Fig 2. Daily global solar irradiation on the tilted surface has estimated as $5.2 \mathrm{kWh}$ per $\mathrm{m}^{2}$ per day from Photovoltaic Geography Information System (PVGIS). The long-term average daily global irradiation ranges from $4.8 \mathrm{kWh} / \mathrm{m}^{2}$ day to 5.8 $\mathrm{kWh} / \mathrm{m}^{2}$ day (Burera, month of May and Nyanza, month of July, respectively) which indicates a high potential for solar energy development.

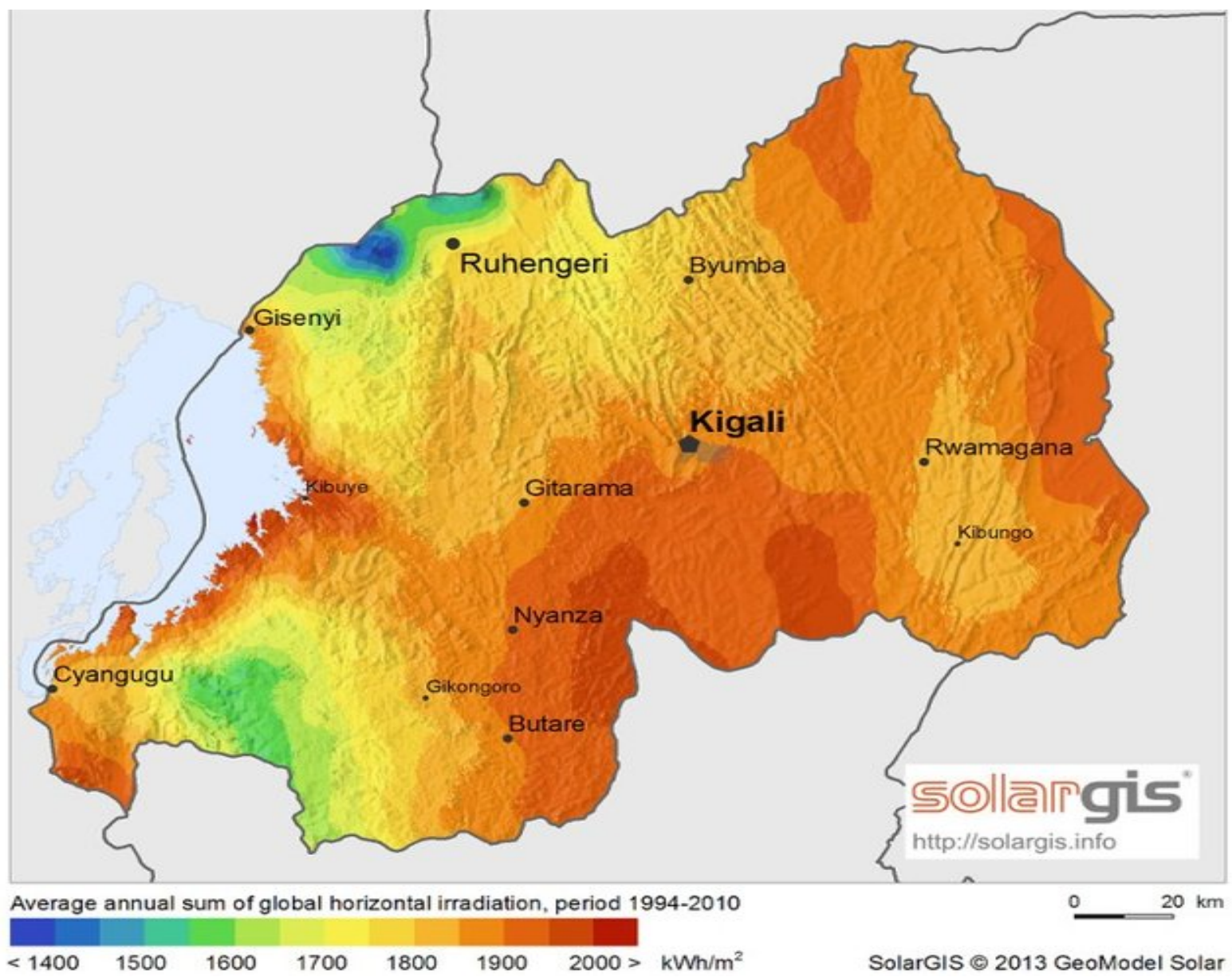

Figure 2. Global horizontal irradiation map for different districts of Rwanda 


\subsection{Case Study}

The Solar PV urban planning project (Gigawatt Global Programme of Activities) was installed renewable solar energy power plant at a site where none existed. The CPP is located in Rwamagana District at the Agahozo-Shalom Youth Village (ASYV). The site is about $80 \mathrm{~km}$ from Kigali, Rwanda's capital. The CPP used solar photovoltaic (PV) modules with a single-axis tracking system. A not-for-profit village is for orphaned children during and after the 1994 Rwandan genocide. The ASYV is a residential community in Rural Rwanda. The CPP has a peak output capacity of 8.5 MWp consisting of 28,340 solar PV modules and covering 16 hectares. The project had net electricity of 15,275 MWh for the first period and the first year of operation of 15,552 MWh. The solar field at the ASYV in Rwanda embodies a range of causes: it helps the long-term development sustainability, it is good for the environment, it generates local job opportunities employment, education and it empowers the country with access to electricity, which will be the results of benefits for the Rwandan population.

In February 2015, the first utility-scale solar energy project in East Africa was commissioned at the ASYV as shown by the fig.2 taken from Gigawatt global, providing 8.5 MW of grid-connected power to 15,000 homes. This increased the total grid capacity by $6 \%$ [6].

The PV Power plant uses 28,360 photovoltaic panels on 20 hectares (49 acres) of land and produces $6 \%$ of the total electrical supply of the country. Off-grid renewable energy systems are not only needed to connect a big number of people with a source of electricity, also appropriate due to geographical constraints and costs for grid extension.

In developed countries including Rwanda, mini-grids are increasingly considered an option to improve energy security, power quality, and reliability, as well as to avoid power blackouts due to natural disasters.

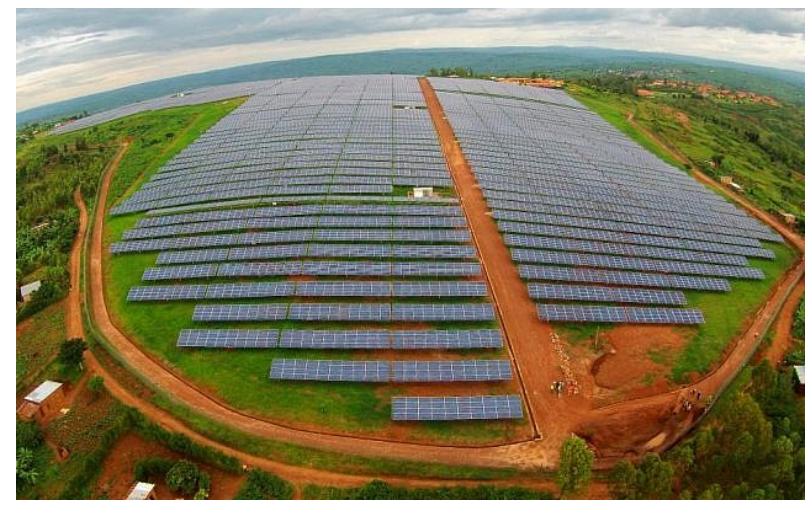

Figure 3. Utility-scale of 8.5MW PV power plant constructed in Agahozo-Shalom Youth Village in Rwanda

The project development was partially funded through grants from the Energy and Environment Partnership (EEP), a partnership of the British, Finnish and Austrian governments and the United States Government via the Overseas Private Investment Corporation's (OPIC) Africa Clean Energy Finance Grant. Astrom Technical Advisors, S.L.

(ATA) served as technical adviser, SEDI Labs served as a key project development partner, with Remote Partners assuming the role of the local project manager.

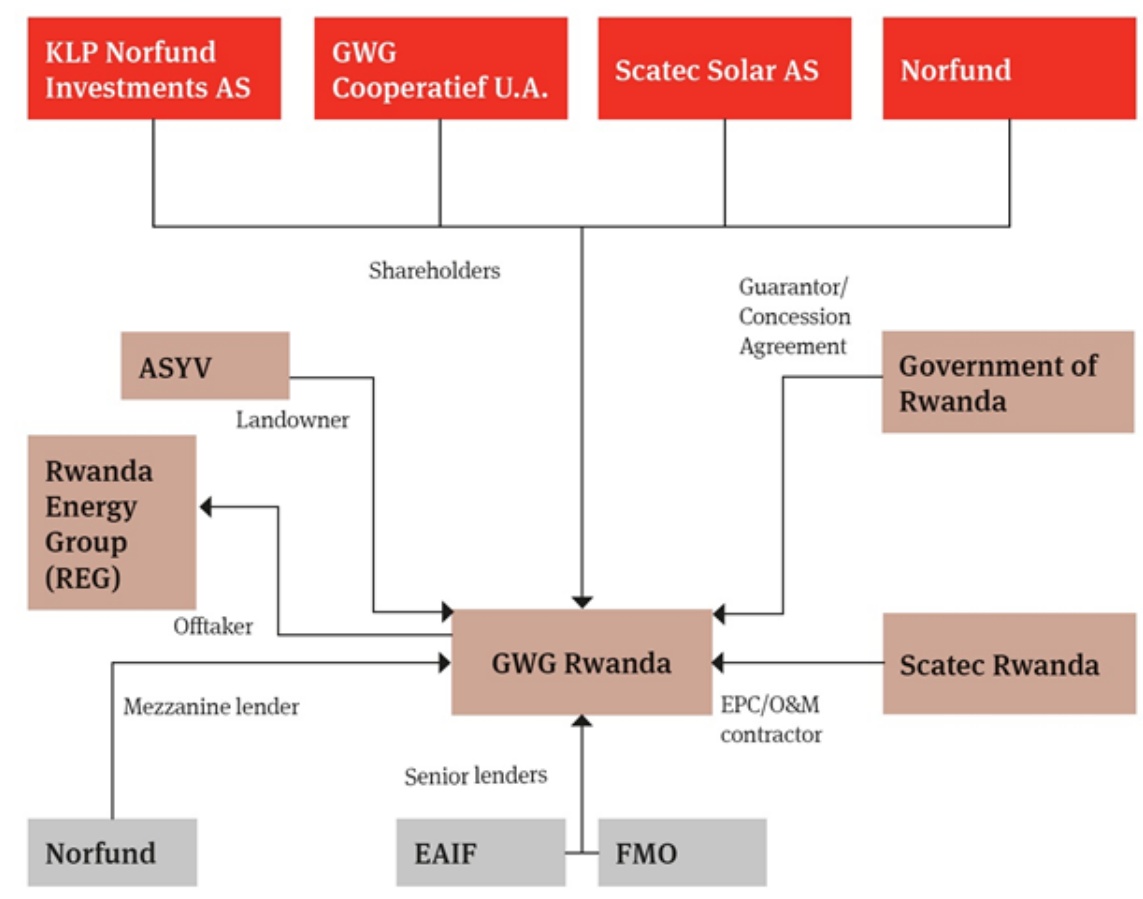

Figure 4. The structure of the transaction 
The Rwanda field brought together an international consortium of financing partners. Debt was provided by FMO (Netherlands Development Finance Company) and the London-based EAIF (Emerging Africa Infrastructure Fund); mezzanine debt provided by Norfund (The Norwegian Investment Fund for Developing Countries); equity from Scatec Solar ASA (who also served as EPC contractor and serves as O\&M provider), Norfund and KLP Norfund Investments (a vehicle jointly owned by KLP, the largest pension fund in Norway, and Norfund). Grants were received from the United States Government via OPIC's ACEF (Africa Clean Energy Finance) grant and from Finland's EEP (Energy and Environment Partnership). Norton Rose Fulbright from London served as international legal counsel.

\subsection{Technical Specifications of the Main Equipment}

Polycrystalline silicon PV modules, of the BYD 300P6C-36 type polycrystalline silicon PV modules type, were used in the implementation of CPP. About 28,340 of such modules will be connected in series consisting of 20 PV modules to form 1,417 strings of parallel connections and produce a nominal capacity 8,502 $\mathrm{kWp}$. The angle of incidence between the incoming sunlight and a photovoltaic panel will be minimized by the single-axis tracking system design that is used to minimize thereby increasing the amount of electricity generated per fixed amount of nominal installed capacity. The P50 forecast for electricity generation for the first year of production is 15,552MWh. A degradation factor of $0.60 \%$ is afterward used to approximate the amount of electricity generated in subsequent years.

The table below highlights the solar PV module characteristics:

Table 1. Solar PV module specifications

\begin{tabular}{|c|c|}
\hline Parameter & Value \\
\hline PV Module type & Si-Poly \\
\hline PV Model & BYD 300P6C-36 \\
\hline Manufacturer & BYD \\
\hline Rated Nominal Capacity & $300 \mathrm{Wp}$ \\
\hline Number of modules & 28340 \\
\hline OperatingVoltage & $600-850 \mathrm{~V}$ \\
\hline Array Efficiency (STC) & $15.47 \%$ \\
\hline & $8.502 \mathrm{kWp}$ \\
\hline Array operating characteristics & $646 \mathrm{~V}, 11812 \mathrm{~A}$ \\
\hline Lifetime & 25 years \\
\hline
\end{tabular}

Direct solar radiation constitutes the major source of solar energy that can be captured by solar Photovoltaic modules.

Since the sun keeps changing its position during the day, the angle by which the direct sun rays hit the solar panels also keeps changing and results in energy losses, especially in the mornings and evenings. Rotating the panels by use of solar trackers helps to minimize the angle of incidence between the incoming sunlight and a photovoltaic panel thereby increasing the amount of energy produced from a fixed amount of installed power generating capacity. A single-axis tracker system, rotating from East to West depending on the position of the sun will be used for this CPP.

\section{Sustainable Development}

Supplying secure energy resources has good advantages but is not enough for the development of a society or country. Furthermore, development requires a sustainable supply of energy resources in the long-term project and sustainable availability at a reasonable cost, also the use without causing negative societal impacts. Supplies of such energy resources as fossil fuels and uranium are generally acknowledged to be finite. Other energy sources such as sunlight, wind and falling water are considered as renewable and therefore sustainable over the relatively long term. Wastes materials and biomass fuels are also usually viewed as sustainable energy sources. In general, the implementation of these statements is numerous and depends on how sustainable is defined. Clearly, a relation exists between environmental impact and energy efficiency for the same services or products that are less resource utilization and pollution normally associated with increased energy efficiency.

Furthermore, being by nature site-specific, they favor a decentralized power system and locally applicable solutions independent of the national network. It enables people to perceive positive and negative energy consumption. Consequently, the small scale of the equipment often makes the time required from initial design to operation short, providing greater adaptability in responding to unpredictable growth and changes in energy demand.

\subsection{Importance of Renewable Energy Resources and Technologies for Sustainable Development}

The exploitation of solar energy resources is a key component of sustainable development. There are two significant reasons for it as follows.

1. They have zero environmental impact compared to other sources of energy.

2. Renewable energy resources can provide reliable and sustainable supply energy almost indefinitely and cannot be depleted unlike fossil fuel and uranium resources.

Uranium resources and fossil fuel are finite and can be finished by extraction and consumption. That is why many deferent renewable energy technologies are potentially available for use in urban areas. 


\subsection{Essential Factors for Sustainable Developments}

The main mission of sustainability is to inspire local and national authorities and incorporate environmental considerations in setting energy program, though being given many deferent meanings in deferent contexts, and embodies a long-term perspective.

Such parameters can be described as follows:

Public awareness: This is the initial step and very crucial in making a sustainable energy program successful. This should be carried out through the media and by public and/or professional organizations.

Information: important informational input on energy utilization, environmental impacts, renewable energy resources, etc. should be provided to the public through public and government channels.

Environmental education and training: This can be implemented as a completing part of the information. Any approach which an integral education and training do not have is likely to fail. That is why this can be considered as a significant prerequisite for a sustainable energy program. For this reason, a wide scope of specialized agencies and training facilities should be made available to the public.

Innovative energy strategies: These should be provided for an effective sustainable energy program and, therefore, require the efficient dissemination of information, based on new methods and consisting of public relations, training, and counseling.

Promoting renewable energy resources: renewable energy sources should be promoted in every stage, in order to achieve environmentally benign sustainable energy programs, which will create a strong basis for the shortand long-term policies.

Financing: Some countries, e.g., Germany and China apply for the support in a different way and simply exempt the people who use such systems and technologies from some portion of their taxes.

Monitoring and evaluation tools: Monitoring and evaluation tools should be successfully used for the program.

\subsection{Analysis of Current Annual Electricity Needs of the Agahozo-Shalom Youth Village}

Rwanda's daily solar irradiation ranges from $4 \mathrm{kWh} / \mathrm{m}^{2}$ north of the city of Ruhengeri to $5.4 \mathrm{kWh} / \mathrm{m}^{2}$ south of the capital, Kigali, in the Southern and Eastern provinces. However, conditions vary from season to season, with average daily irradiation levels in the cloudy reaching about $4.5 \mathrm{kWh} / \mathrm{m}^{2}$. Total annual potential is estimated to be around 66.8 TWh. In February 2019, the first utility-scale solar energy project in East Africa was commissioned at the Agahozo-Shalom Youth Village in Rwanda, providing 8.5 MW of grid-connected power to 15,000 homes. This increased total grid capacity by $6 \%$.

\section{Conclusions}

Sustainable development is related to the utilization of renewable energy resources. Cites and countries should put much effort into discovering sustainable energy resources and environments in terms of renewables. The Solar PV urban planning project (CPP) forms part of the Gigawatt Global Program of Activities, hereinafter "Gigawatt Global PoA" which their purpose is to promote the development that is the sustainability of grid connected renewable energy projects in Rwanda. The CPP is located in Rwamagana District, at the ASYV, approximately nine kilometers from the main Kigali- Kagitumba highway.

The CPP will, therefore, reduce $\mathrm{CO}_{2}$ emission by replacing Electricity generated by fossil fuel-based power plants connected to the national electricity grid. The project is expected to achieve average annual emission reductions of about 9,470 $\mathrm{tCO}_{2} \mathrm{e}$ and a total of 66,289 $\mathrm{tCO}_{2} \mathrm{e}$ during the first crediting period.

The implementation of the CPP contributed to sustainable development in the following ways:

- $\quad$ The project is expected to provide reliable electricity to the national electricity grid. This is in line with Rwanda's Vision 2020, which places infrastructural advancement and energy generation as one of the pillars that are necessary for transforming Rwanda to A middle-income earning economy (Rwanda Vision 2020).

- The project is expected to create new local job opportunities during the construction and operation phase.

- The project will balance in improving the hydrocarbon trade through the reduction of oil imports used for electricity generation.

- The project will result in the transfer of state-of-the-art technology in utility-scale power generation from solar PV sources to the Rwandan population. The transfer of technology and know-how will be directly replicable to other future solar PV energy projects.

\section{Appendix}

\section{The Socioeconomic Impact:}

With an increase of $6 \%$ in its electrical capacity Rwanda continues to benefit significantly from improved social welfare in the country, increased economic output and employment conditions, and improved standard of living conditions for residents. The project has also minimized the environmental impact from new energy production. 


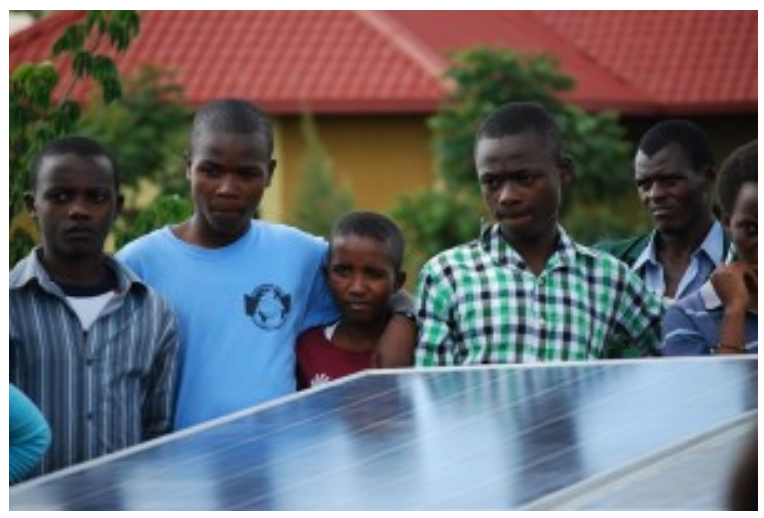

Figure 5. Rwanda's most vulnerable children, is leasing land to house the solar facility, the fees from which will help pay for a portion of the Village's charitable

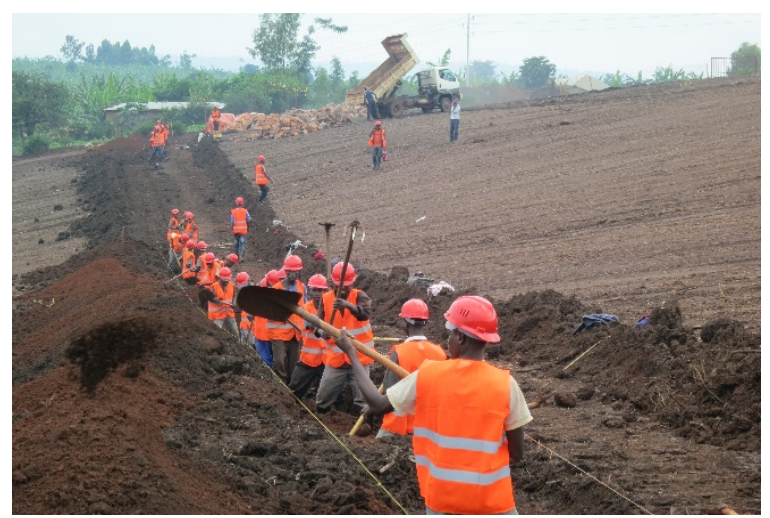

Figure 6. Local Job Opportunities

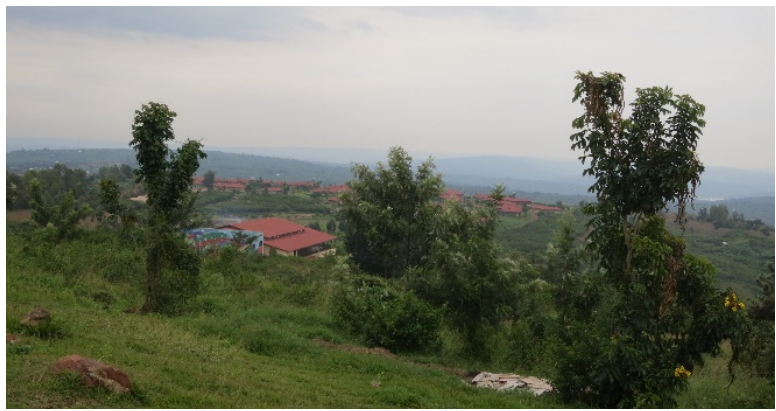

Figure 7. Agahozo-Shalom Youth Village developed

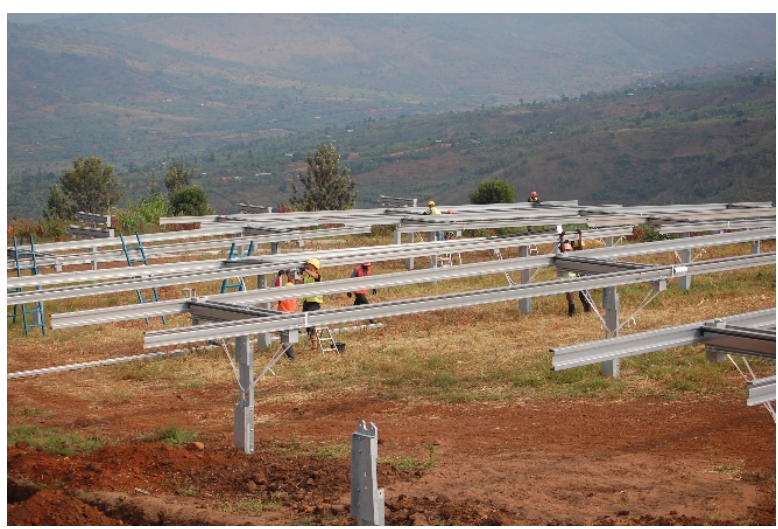

Figure 8. CPP under Construction in the cafeteria at the Agahozo-Shalom Youth Village

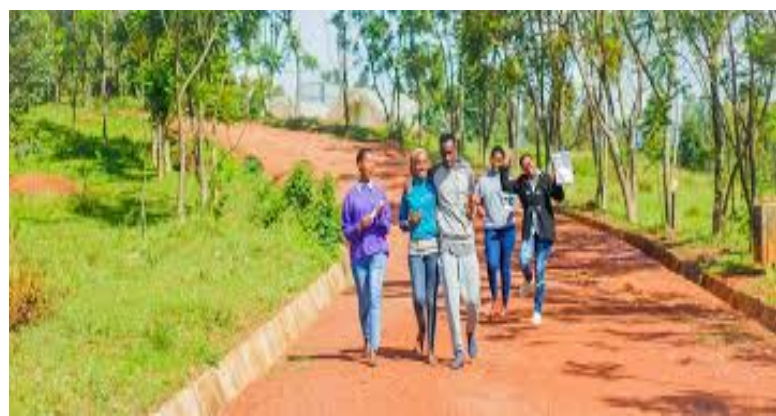

Figure 9. The goal of the Village is to restore hope and opportunity to traumatized young lives

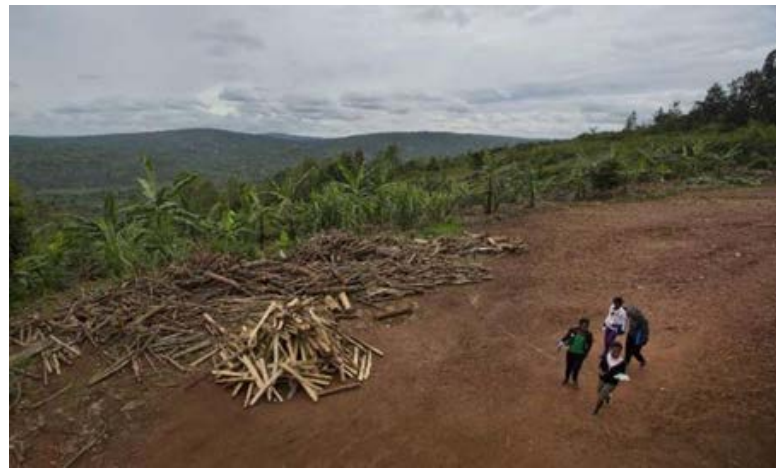

Figure 10. A group of Rwandan students return to their dormitories after having lunch

\section{REFERENCES}

[1] Ameur, K. Loudiyi, A. Khallaayoun and M. Aggour, "Dynamic Modelling of a Solar PV plant," Renewable Energies Grid Integration Department, vol. 1, no. 9, pp. 1-5, 2015.

[2] Anon. Urban energy handbook. Paris: Organisation for Economic Co-Operation and Development (OECD), 1995.

[3] Dincer I, Rosen MA. A worldwide perspective on energy, environment and sustainable development. International Journal of Energy Research 1998; 22(15):1305-21.

[4] http://www.africa-eu-renewables.org/market-information/r wanda/renewable-energy-potential. [Accessed 19 January 2017].

[5] Jaeger, C.; Paroussos, L.; Mangalagiu, D.; Kupers, R.; Mandel, A.; Tàbara, J. A New Growth Path for Europe: Generating Prosperity and Jobs in the Low-Carbon Economy; Synthesis Report; European Climate Forum e.V.: Potsdam, Germany, 2011.

[6] Jalali, V.E., Moti Birjandi, A.A., (2010). A look at pure energies and adaptable constructs with the environment in desining cities and buildings, The fourth seminar, Shahid Rajaii University, Tehran, Iran. 